DOI: http://dx.doi.org/10.5007/2175-8069.2016v13n29p157

\title{
A imagem do profissional contábil: análise da percepção socialmente construída por estudantes de ciências econômicas
}

The accountant image: an analysis of socially constructed perception by economics students

La imagen del profesional contable: análisis de percepción socialmente construido por estudiantes de economía

\section{Susana Cipriano Dias Raffaelli}

Doutoranda em Controladoria e Contabilidade pela Universidade de São Paulo Mestre em Contabilidade pela Universidade Federal do Paraná

Endereço: Av. Professor Luciano Gualberto, n॰ 908, Butantã

CEP: 05.508-900 - São Paulo/SP - Brasil

E-mail: susanadias@usp.br

Telefone: +55 (11) 3091-5820

\section{Márcia Maria dos Santos Bortolocci Espejo}

Doutora em Controladoria e Contabilidade pela Universidade de São Paulo

Professora do Programa de Pós-Graduação em Administração da Fundação Universidade Federal de Mato Grosso do Sul

Endereço: Av. Sen. Filinto Müler, n॰1555, Vila Ipiranga

CEP: 79.074-460 - Campo Grande/MS - Brasil

E-mail: marcia.bortolocci@ufms.br

Telefone: + 55 (67) 3345-3922

\section{Henrique Portulhak}

Doutorando em Contabilidade pela Universidade Federal do Paraná

Professor Assistente do Departamento de Contabilidade da Universidade Federal do Paraná Endereço: Av. Prefeito Lothário Meissner, n 632, Jardim Botânico

CEP: $80.210-170$ - Curitiba/PR - Brasil

E-mail: henrique.portulhak@ufpr.br

Telefone: + 55 (41) 3360-4417

Artigo recebido em 07/07/2015. Revisado por pares em 25/07/2016. Reformulado em 08/08/2016. Recomendado para publicação em 11/08/2016 por Sandra Rolim Ensslin (Editora Científica). Publicado em 26/08/2016. 
Resumo

A pesquisa averiguou, com base na Teoria da Representação Social, a imagem socialmente construída do profissional contábil por graduandos em Ciências Econômicas. Foram coletados dados primários por meio de questionário composto por questões abertas, fechadas e fotoquestionário, aplicado a estudantes do último período do curso de graduação em Ciências Econômicas de uma universidade pública. Os dados foram analisados com a aplicação da metodologia do discurso do sujeito coletivo e por técnicas de estatística descritiva. A análise dos dados relevou as características dos profissionais contábeis pela visão dos estudantes de Ciências Econômicas sob diversas perspectivas, como características físicas, profissionais e comportamentais, bem como a percepção sobre as atividades exercidas pelos profissionais em Contabilidade. Os resultados apresentados podem possibilitar ações de órgãos representativos da classe contábil visando valorizar aspectos positivas e mitigar efeitos negativos resultantes de possíveis estereótipos ligados à atividade e ao profissional de Contabilidade.

Palavras-chave: Representação social. Imagem. Profissão contábil.

\begin{abstract}
This research found, based on the Theory of Social Representation, the socially constructed image of professional accounting by graduates in Economics. Data were collected through a questionnaire applied to students in the last period of the undergraduate course in Economics of a Brazilian public university. Data were analyzed with the application of collective subject discourse methodology and descriptive statistics. Data analysis showed characteristics of accounting professionals from the view of students of Economics from different perspectives, such as physical, occupational and behavioral, as well as the perception about the activities carried out by these professionals. Results can allow actions from representative boards of accountants to enhance positive aspects and mitigate negative effects of possible stereotypes associated with the activity and the accounting professional.
\end{abstract}

Keywords: Social representation. Image. Accounting professional.

\title{
Resumen
}

El estudio investigó, en base a la teoría de la representación social, la imagen construida socialmente del profesional contable por estudiantes de graduación en economía. Se recogieron los datos primarios a través de un cuestionario, compuesto de preguntas abiertas, cerradas y fotoquestionário, que se aplicó con los alumnos del último periodo del curso de licenciatura en economía en una universidad pública. En el análisis de datos, se aplacó características de los profesionales de la contabilidad por la perspectiva de los estudiantes de Economía desde diferentes perspectivas, como la física, ocupacional y del comportamiento, así como la percepción de las actividades realizadas por los profesionales de la contabilidad. Los resultados pueden permitir a los órganos de representación de la clase contable a acciones dirigidas a potenciar los aspectos positivos y mitigar los efectos negativos de posibles estereotipos relacionados con la actividad de contabilidad y el profesional contable.

Palabras clave: Representación social. Imagen. Profesión contable. 


\section{Introdução}

A Contabilidade é entendida como a linguagem dos negócios. Utilizando-se de arcabouço teórico e de procedimentos próprios da Ciência Contábil, esse profissional possui o papel de mensurar, avaliar e reportar os eventos econômicos das entidades, com a principal finalidade de prover informações úteis e confiáveis para tomada de decisão dos diversos stakeholders relacionados a essas entidades.

Dessa forma, a Contabilidade possui um papel importante no relacionamento entre a entidade e seu ambiente próximo e remoto, onde se incluem diversos indivíduos e organizações, estando presentes, nesse conjunto, profissionais também ligados à área de negócios, como os economistas e os administradores. Nesse sentido, é possível presumir que a reputação do profissional contábil é um fator relevante para que os usuários da informação contábil, sejam eles internos e externos à organização, atribuam confiabilidade às informações a eles destinadas, o que também pode influenciar o relacionamento entre entidade e seu ambiente e na busca da eficiência dentro das organizações.

Conforme definição constitutiva, descrita por Ferreira (2010), o termo reputação remete ao conceito de que goza uma pessoa por parte de um público. A Teoria das Representações Sociais, segundo Reis e Bellini (2011), fornece uma leitura sobre como as pessoas conceituam ou como os indivíduos - com a tentativa de apreender a realidade buscam informações consideradas válidas pelo grupo de convívio para atribuir significado ao que era inacessível. Depreende-se, assim, que a reputação pode ser socialmente construída, de acordo com as informações que determinado grupo possui para gerar juízo de valor.

A teoria supracitada ainda é pouco utilizada no campo da Contabilidade. Sobre as pesquisas realizadas no Brasil que utilizaram a Teoria das Representações Sociais como referências para verificar a imagem que a sociedade e o próprio contabilista possuem a respeito do profissional contábil, essas não indicam convergência de resultados. Enquanto a pesquisa de Dias e Martins (2005), com foco no olhar da sociedade para o profissional contábil, capturou uma imagem negativa, as investigações de Guerra et al. (2011), com foco na visão do contador para sua classe, e de Reis et al. (2015), com foco na percepção dos discentes do curso de Ciências Contábeis sobre o profissional contábil, encontraram o inverso. Uma possível explicação para a diferença entre os achados deve-se ao ponto de referência de observação de cada agente. No primeiro trabalho, o observador está distante na realidade observada. Já nos dois casos a seguir, o observador está, de alguma forma, imerso nessa realidade. Desse modo, realizar uma pesquisa em que o observador esteja em uma posição intermediária pode ser relevante à medida que tenha condições de capturar a imagem da profissão contábil de um ângulo distinto, acrescentando novas evidências sobre a reputação desse profissional e buscando afastar limitações observadas nas pesquisas já realizadas.

Diante da proximidade dos economistas com o campo contábil, tem-se, nesses agentes, a possibilidade de observação da profissão contábil na condição intermediária sugerida, já que os primeiros podem atuar ativamente no contexto no qual atua o profissional em Contabilidade, seja no ambiente interno ou externo às entidades, e, até mesmo, considerando a interação desses profissionais no meio acadêmico por conta das sinergias existentes entre as áreas científicas, como observa Guerreiro (1991) nas discussões relacionadas à definição e mensuração do lucro, bem como no desenvolvimento da Teoria Positiva da Contabilidade que, de acordo com Watts e Zimmerman (1986), também contou com o apoio de princípios 
oriundos da teoria econômica, fazendo com que a adequada interação entre os profissionais traga reflexos positivos tanto em âmbito acadêmico quanto no campo profissional.

A criação de barreiras nesse processo de interação pode ser prejudicial para ambas áreas, como pela existência de estereótipos. Como exemplo: ao tratar sobre a mensuração contábil e econômica do lucro, Guerreiro $(1991$, p. 2) traz a observação realizada por Chang (1962) sobre a dificuldade de se chegar a um denominador comum entre as áreas a respeito da mensuração e da definição do lucro, afirmando que "[...] os contadores queixam-se que os economistas são muito idealistas e que seus conceitos são impraticáveis, e os economistas, por sua vez, afirmam que os contadores são muito mecânicos e seus procedimentos não são baseados em princípios sólidos". Dessa forma, conhecer a representação social formada pelos economistas, logo no final do seu processo formativo, a respeito do profissional contábil, pode ser importante para a identificação de estereótipos formados desde os bancos escolares e que possam ser mitigados para que sejam viabilizados canais de comunicação eficazes entre os grupos de profissionais. Diante do exposto, faz-se o seguinte questionamento: Qual a imagem do profissional contábil socialmente construída por graduandos em Ciências Econômicas? Dessa forma, a presente investigação tem por objetivo identificar, tomando como base a Teoria das Representações Sociais, a percepção de graduandos em Ciências Econômicas a respeito do profissional em Contabilidade e das atividades exercidas por esse profissional.

A temática exposta na questão de pesquisa já foi abordada em pesquisas internacionais, dentre as quais é possível destacar inicialmente as realizadas por Beard (1994) e por Evans e Fraser (2012), que buscaram evidenciar por meio de artefatos da cultura popular, como filmes e literatura, as formas como o profissional contábil é retratado. Allen (2004), por sua vez, investigou a importância da imagem do contador no processo de tomada de decisão quanto à carreira profissional e, por conseguinte, com relação ao perfil dos estudantes que ingressam no curso de Ciências Contábeis. Rogers, Dillard e Yuthas (2005) ocuparam-se em investigar o impacto de escândalo financeiro da empresa Enron na imagem e reputação do profissional contábil, alertando sobre a necessidade de ações para reestruturação da reputação abalada. Os trabalhos citados convergem no que se refere à importância de mapear a percepção de diversos atores sociais sobre o contador como uma ação necessária para fortalecer a profissão e propiciar o desenvolvimento da ciência.

No que tange ao fortalecimento da profissão contábil, é possível notar, conforme descreve Jovchelovitch (2000), que as tipificações não apenas surgem da convivência social, mas também podem contribuir para determinar as relações entre os sujeitos que integram a sociedade. Desse modo, o papel do profissional contábil nas organizações pode ser influenciado por tipificações preconcebidas pelos gestores sobre o primeiro. Assim, compreender qual a concepção dos gestores sobre a imagem do contador pode auxiliar as instituições de ensino superior e aos órgãos reguladores e representativos para realização de ações que possibilitem o fortalecimento da imagem do contador em geral perante indivíduos, categorias profissionais e organizações, favorecendo a redução da dissonância cognitiva entre o real e o imaginário e possibilitando melhor interação entre os profissionais da área de negócios.

Ademais, o desenvolvimento de melhor interação pode propiciar melhor comunicação entre contabilistas e profissionais das demais áreas de negócios, possibilitando mais legitimidade conferida às informações contábeis fornecidas aos demandantes destas. Considerando, nesse contexto, a participação de economistas no universo de usuários de 
informações contábeis e considerando, como descrito por Hendriksen e Van Breda (1999), a função da Contabilidade em fornecer informações úteis à tomada de decisão de tal universo, espera-se, ao alcançar o objetivo geral proposto, colaborar para o avanço da Ciência Contábil no sentido de possibilitar reflexões passíveis de serem transformadas em ações que possam auxiliar a Contabilidade a atingir sua finalidade.

O artigo é estruturado da seguinte forma: (i) introdução, com a contextualização, problematização, questão de pesquisa, objetivos e justificativas sobre a relevância da investigação; (ii) referencial teórico, que trata da Teoria das Representações Sociais e da percepção da imagem do profissional contábil de acordo com estudos empíricos já realizados; (iii) apresentação dos procedimentos metodológicos adotados para a realização da pesquisa; (iv) análise dos dados coletados; e (v) conclusões, limitações dos resultados e sugestões para futuras investigações.

\section{Teoria das Representações Sociais}

A Teoria das Representações Sociais teve origem na década de 1950, com base em estudos realizados, no campo na Psicologia Social, pelo francês Serge Moscovici. Nesse período, o autor divulgou os resultados de uma pesquisa em que, por meio de uma nova interpretação do conceito de representações coletivas enunciado pelo sociólogo alemão Émile Durkheim, verificou como a psicanálise passou a ter significação para grupos populares da França. Esse trabalho teve tradução para a língua inglesa apenas em 1961, quando se inicia de fato a disseminação da teoria, tendo a autora Denise Jodelet como sua principal propagadora (GAMA; SANTOS; FOFONCA, 2010).

A primeira obra de Serge Moscovici, traduzida para o português, é intitulada "A Representação Social da Psicanálise" e foi publicada em 1978. Nessa obra, o autor conceitua a representação social como o esforço do ser humano em compreender a realidade (MOSCOVICI, 1978). Jodelet (2001) descreve esse conceito como conhecimentos práticos manifestos por meio de signos, formados e partilhados por indivíduos em um determinado contexto social, tornando-se elementos constitutivos da realidade da vida cotidiana. Para melhor compreensão desse conceito, faz-se necessário compreender a que se referem as expressões "realidade" e "vida cotidiana".

A realidade pode ser definida como a certeza coletiva de que algo existe. Essa certeza é qualificada pelo conhecimento do senso comum, conceituado por Berger e Luckmann (2003) como o conjunto de entendimento socialmente partilhado que confere significado à ação humana. Tais significados propiciam a organização da vida cotidiana representada pela formação de um mundo coerente, resultante da compreensão dos indivíduos dessa realidade. De acordo com essa abordagem, o mundo da vida cotidiana é produto do pensamento e da ação humana. O pensamento pode ser estabelecido como um processo subjetivo, e o produto da ação humana, ou a realidade, como a objetivação do pensamento.

Para Berger e Luckmann (2003), a vida cotidiana é uma esfera da realidade vivenciada por diversos indivíduos. Estes, ao relacionarem-se face a face, tornam sua subjetividade acessível ao outro, enquanto também acessam a subjetividade de outrem. Nesse processo de reciprocidade e interação, a linguagem gestual, falada e escrita, possui papel fundamental como componente do processo de significação. Por meio dela, quando os processos citados são contínuos, possibilita a construção de padrões, de categorias e tipificações. Os autores 
esclarecem ainda que as construções referidas fazem parte do conjunto de conhecimentos que permitem a resolução de problemas de rotinas. Nesse sentido, há um processo de maior aprimoramento de conhecimento relativo a questões próximas ao trabalho dos indivíduos, enquanto se possui conhecimento superficial do mundo de trabalho dos outros.

Ao tecer essas redes de conhecimentos, o ser humano, como esclarece Teves e Rangel (1999), está formando as representações sociais. Com base nessa observação, compreende-se a Teoria das Representações Sociais como a teoria do senso comum, tendo em vista que Moscovici (2007) buscou compreender como esse fenômeno é formado em uma sociedade e, para tanto, desenvolveu um método de estudo que considera o imaginário coletivo. Os pressupostos dessa teoria, conforme descrito por Guerra et al. (2011), são de que o universo exterior e o universo interior do indivíduo não são dissociados, sendo o objeto - componente do universo externo - produção do sujeito, estando ambos inseridos em um campo comum. Assim, o autor constrói sua teoria compreendendo o ser humano como diverso e imerso em um ambiente complexo e de incerteza.

O indivíduo busca absorver a realidade complexa em que está inserido, dando significado aos fenômenos observados. Moscovici (2007) afirma que esses significados são formados coletivamente, mediante informações tidas como consensuais sobre a realidade, construindo representações sociais. Sendo assim, as representações sociais constituem uma estrutura organizada de conhecimento, possibilitando ao homem a compreensão da realidade, das interações da vida cotidiana, além das novas criações. Assim, em consequência, o significado dado a um fenômeno, como uma opinião positiva ou negativa a respeito de um determinado assunto, além de revelar a representação social formulada por um indivíduo sobre um objeto, influencia diretamente em sua atitude com outras pessoas e com outras representações sociais (RIBEIRO; ANTUNES-ROCHA, 2016).

O processo de formação das representações está fundamentado, de acordo com a teoria de Moscovici (2007), nos conceitos de ancoragem e objetivação. O primeiro conceito aborda a ação de tornar uma noção abstrata em uma forma organizada de conceito, categorizando-o e relacionando-o a uma rede lógica. A objetivação trata de trazer esses conceitos não conhecidos a um plano palpável, unindo-os aos conhecimentos pré-existentes (GONDIM; FISCHER, 2009).

Moscovici (2007) explica que as representações tornam o não familiar em familiar. Esse processo tem, como base fundamental, a soma das memórias e das experiências comuns. A ancoragem permite o movimento constante da memória à medida que possibilita o intercâmbio de pessoas, objetos e acontecimento, categorizando-os de acordo com os conceitos e estereótipos formulados anteriormente. O autor trata o processo de ancoragem como dirigido para dentro, pois essa etapa ainda não é exteriorizada. A exteriorização ocorre no processo de objetivação, passando a ser intitulado por Moscovici (2007) como direcionado para fora, pois retira os conceitos e imagens formulados da etapa anterior para transmitir ao mundo exterior. Com isso, o processo exposto impede que as modificações de uma representação sejam abruptas.

A formação das categorias e conceitos que ocorrem no processo de ancoragem advém de estímulos provenientes das relações sociais, podendo ocorrer por meio dos veículos de comunicação como jornais, televisão, rádio, conversações e rituais, ou então pelas organizações sociais como igrejas e partidos políticos (JOVCHELOVITCH, 2000; MOSCOVICI, 2007; GUERRA et al., 2011). 
$\mathrm{Na}$ visão de Jovchelovitch (2000), as representações sociais não são simplesmente criadas pelas relações sociais, mas também determinam essas relações num processo de recursividade. Depreende-se, assim, que a ideia, ou interpretação de determinado fato social, objeto ou indivíduo, além de ser construído pela sociedade, pode influenciar a forma com que o grupo se relacionará com tais fatos e sujeitos, constituindo um processo de influência simultânea entre estes, em que ora as relações afetam as interpretações, ora os significados atribuídos afetam as interações entre as partes.

Dessa forma, a importância dos estudos em representações sociais é sintetizada em três principais motivos por Ribeiro e Antunes-Rocha (2016), tomando como base a obra de Moliner e Guimelli (2015): (i) compreender as lógicas sociais em que a representação construída de um objeto justifica a lógica social de ação e identifica as crenças e opiniões que a sustenta; (ii) conhecer uma representação social facilita a adoção de estratégias de comunicação; e (iii) possibilitar o entendimento das orientações das trocas sociais e das mudanças de comportamento.

Tendo em vista a característica das representações sociais, o processo de elaboração social desta e a sua importância na relação entre agentes e objetos sociais, faz-se necessário compreender como a teoria exposta tem sido utilizada para compreender a imagem do profissional contábil.

\subsection{A Imagem do Profissional Contábil em Pesquisas Empíricas}

Os conceitos abordados por Moscovici (2007) têm sido aplicados no campo da contabilidade para demonstrar a percepção da sociedade, dos usuários da Contabilidade e dos próprios contadores sobre a profissão contábil. Destacam-se, em âmbito nacional, os trabalhos de Dias e Martins (2005), de Guerra et al. (2011) e de Reis et al. (2015) como exemplos de pesquisas que fizeram uso da Teoria das Representações Sociais para fundamentar suas análises.

Dias e Martins (2005) buscaram descrever como a sociedade em geral compreende a profissão contábil. Para tanto, os autores utilizaram abordagem fenomenológica e a metodologia de análise de discurso, utilizando a técnica focus group para coleta de dados. $\mathrm{O}$ trecho a seguir refere-se aos achados da pesquisa citada:

O contador é um ser misterioso, não agrega valor, mas tem uma moral incrível com o dono, o acionista. Burocrático, muda de nome, passa a ser um controller, se embasa teoricamente. Vinculado a um processo extremamente simples, é visto como revestido de idoneidade. Entretanto, diz ser o contador aquele que sabe o custo de tudo e o valor de nada, é a pessoa a quem se pode pedir um "jeitinho" (DIAS; MARTINS, 2005, p. 26)

O trabalho de Guerra et al. (2011) mapeou a autoimagem dos profissionais contábeis por meio de entrevistas com contabilistas da região da cidade de Maringá (Paraná). Os achados da pesquisa levaram à seguinte descrição do profissional contábil: amigo, responsável e ético, que atua numa área em constante evolução, cheia de desafios e adorada por quem a pratica.

Já o estudo realizado por Reis et al. (2015), com discentes do curso de graduação em Ciências Contábeis de instituições de ensino superior pública do estado de Minas Gerais, buscou identificar a representação social formulada por estes a respeito das habilidades e 
competências necessárias para um profissional contábil. De acordo com os resultados da investigação, o grupo considera que os profissionais contábeis necessitam desenvolver habilidades e competências pessoais, dotado de condutas éticas, organização para o trabalho, responsabilidade em suas ações, comprometimento com a profissão e conhecimento teórico tanto sobre sua área quanto em áreas afins, sendo que as competências técnicas são mais valorizadas pelos discentes iniciantes e as competências pessoais são mais valorizadas pelos discentes em fase de conclusão de curso.

Também foram identificados trabalhos com outras bases teóricas, como os de Azevedo, Cornacchione e Casa Nova (2008), Azevedo (2010), Splitter e Borba (2014), Oliveira (2014) e Leal et al. (2014). O primeiro investigou a percepção de estudantes da área de Ciências Sociais Aplicadas do estado de São Paulo sobre a imagem de estudantes de Ciências Contábeis. Estes foram considerados organizados e com habilidade para trabalhar com números, mas com baixa capacidade criativa, de relação interpessoal, de liderança e de dedicação aos estudos. Azevedo (2010), com o objetivo de mapear a percepção pública do contador, criou, com base na literatura pré-existente, categorias de análises (dedicação aos estudos, criatividade, trabalho em equipe, ética, propensão ao risco, liderança, comunicação e trabalho em equipe). Essas categorias foram utilizadas na elaboração de um fotoquestionário, utilizado como instrumento de pesquisa de campo envolvendo 1.034 respondentes escolhidos de forma aleatória. Os achados revelaram forte autocrítica do contador a respeito dos quesitos "liderança" e "trabalho em equipe", sendo a percepção interna sobre trabalho em equipe um ponto negativo. Ainda, verificou-se que o contador possui percepção positiva no quesito "dedicação aos estudos".

Já o artigo de Splitter e Borba (2014), realizado com estudantes e professores de cinco cursos de graduação de duas universidades do estado de Santa Catarina, buscou identificar a imagem da atividade profissional do contador sob a ótica da teoria dos estereótipos, revelando a visão de que o contador realiza atividades pouco interessantes, repetitivas, baseadas na realização de cálculos e cumprimento de normas, e que o profissional é considerado introspectivo, pouco crítico e pouco comunicativo. O estudo de Oliveira (2014) procurou identificar como o mercado profissional avalia o contador e a Contabilidade no ambiente de negócios, utilizando como base a sociologia das profissões. Os resultados da pesquisa apontaram que gestores vinculam e avaliam positivamente a atividade do contador com aspectos fiscais e tributários, ética profissional e conhecimento técnico, contudo avaliam negativamente a respeito do entendimento do negócio, liderança e comunicação. Por fim, a investigação de Leal et al. (2014), também baseada na teoria dos estereótipos, investigou a percepção de estudantes de Ciências Contábeis e do público externo sobre os profissionais contábeis em uma cidade do estado de Minas Gerais, o que revelou uma tendência de maior autocrítica sobre o profissional contábil por parte dos estudantes em comparação ao público externo, revelando uma imagem, em geral, não negativa.

Segundo Azevedo (2010), é possível verificar a existência de estudos relacionados à imagem dos profissionais contábeis em âmbito internacional desde a década de 1950 - como, por exemplo, as realizadas por Robert (1957) e Stacey (1958) -, quando os contabilistas foram descritos como competentes, habilidosos com cálculos, metódicos e comprometidos com atividades de rotina. As pesquisas desenvolvidas entre as décadas de 1960 e 1980 seguiram, essencialmente, as mesmas descrições do que foi observado na década de 1950, contudo, por sua vez, ampliando as observações relacionadas ao lado emocional, descrevendo 
o profissional como passivo, sem habilidades sociais, tímido, insensível e submisso (DECOSTER; RHODE, 1971, ARANYA; MEIR; BAR-ILAN, 1989).

Já na década de 1990, observou-se uma ampla publicação de pesquisas que fundamentaram suas análises em filmes, novelas e séries (CORY, 1992; BEARD, 1994; HOLT, 1994; SMITH; BRIGGS, 1999). Essas pesquisas corroboram os achados das pesquisas anteriores, abordando, além das dimensões destacadas, o imaginário social com relação às características físicas do contador. Como resultado, o profissional contábil foi descrito como homem de meia-idade, com pouco cabelo, baixa estatura e usam óculos. As pesquisas subsequentes, em sua maioria, mantiveram semelhantes conclusões com relação aos aspectos descritos anteriormente, ampliando as discussões sobre honestidade dos contabilistas, criatividade, dedicação aos estudos, entre outros. Também se inicia maior discussão sobre a ética desse profissional, ora apresentados com posturas positivas, ora negativas (ALBRACHT; SACK, 2000; PARKER, 2000; FRIEDMAN; LYNE, 2001; FRANCISCO; NOLAND; KELLY, 2003; NOEL; MICHAELS; LEVAS, 2003; HUNT; FALGIANI; INTRIERI, 2004; SUGAHARA; KURIHARA; BOLAND, 2006; DIMKIT; FELTON, 2006; VAIVIO; KOKKO, 2006; DIPTYANA; DJUWARI, 2007; SCHLEE et al., 2007; JEACLE, 2008; BALDVINSDOTTIR et al., 2009; HOOPER; KEARINS; WELLS, 2009; CARNEGIE; NAPIER, 2010).

Os trabalhos citados contribuem para discussão sobre a imagem dos contabilistas, porém muitos possuem escopo teórico diferente ao abordado na pesquisa em tela. Conforme salientado no presente relatório, a Teoria da Representação Social teve origem na França, começando a ser divulgada nos Estados Unidos a partir da década de 1960. Esse fato pode justificar o motivo pelo qual muitos dos autores citados tenham fundamentado suas pesquisas no conceito de estereótipo presente na teoria cognitivista que, segundo Pepitone (1981), possui base ontológica positivista, tendo como característica a busca por leis universais capazes de explicar o comportamento social. Essa corrente de pesquisa, tradicional na América do Norte, desconsidera as influências de fatores socioculturais na formação da percepção da realidade, considerando a existência de uma única realidade verdadeira (FERREIRA, 2010). Essa discussão diferencia-se da concepção aqui apresentada, que possui arcabouço ontológico construtivista, considerando como representação social o processo contínuo de significação da realidade, não havendo apenas uma realidade verdadeira, mas diversas realidades.

\section{Procedimentos Metodológicos}

A presente pesquisa possui delineamento metodológico fenomenológico, sendo classificada quanto aos objetivos como exploratória, com dados primários coletados por meio de questionário composto por quatro blocos (MARTINS; THEÓPHILO, 2007). Com relação à composição do questionário, o primeiro bloco buscou capturar a base para formação do discurso coletivo sobre a imagem dos profissionais contábeis por estudantes de Ciências Econômicas, sendo composto pela seguinte questão aberta: "Imagine um profissional contábil. Transcreva o seu pensamento com relação à imagem desse profissional".

A estratégia abordada para análise do primeiro bloco foi a técnica do discurso do sujeito coletivo. Esse método foi desenvolvido por Lefevre e Lefevre (2005) e permite que, com base em descrições individuais sobre determinado tema, possa ser formado o discurso 
coletivo, mantendo-se o sentido primário do discurso individual e respeitando o sentido compartilhado pela coletividade (GONDIM; FISCHER, 2009). Assim, a análise desse bloco seguiu os passos indicados por Lefevre e Lefevre (2005), iniciando pela leitura e transcrição das respostas obtidas. $\mathrm{Na}$ sequência, foram grifadas as expressões-chave das respostas individuais, que foram analisadas e classificadas de acordo com as ideias centrais relativas a cada expressão, formando dessa forma grupos de ideias centrais. Em seguida, com base nessas informações, foi construído o discurso do sujeito coletivo.

Conforme orientado por Lefevre e Lefevre (2005), foi mantido o sentido literal expresso pelos indivíduos nas duas primeiras etapas. Nas demais análises, seguiu-se a interpretação dos pesquisadores, buscando manter coerência no agrupamento de fragmentos para construção de um único discurso. Os autores lembram que, apesar da possibilidade de análises quantitativas das informações obtidas, a formação do discurso do sujeito coletivo se dá por meio de todas as menções realizadas, ainda que um só sujeito tenha enunciado. Isso ocorre haja vista a técnica considerar que cada sujeito possui experiências individuais que contribuem para formar sua perspectiva de realidade, que é formada por meio de relações sociais. Dessa forma, é possível entender que sua voz torna-se o eco de outras vozes.

O segundo bloco do questionário é formado por doze questões fechadas de múltipla escolha, estruturadas de acordo com a escala Likert. As questões foram formuladas com o objetivo de mapear elementos que possam ter contribuído para a formação do discurso coletivo enunciado, tais como: (i) a compreensão sobre o que é a Ciência Contábil; (ii) o grau de conhecimento em Contabilidade dos respondentes; (iii) a proximidade dos respondentes com profissionais da área; e (iv) o tempo de convivência entre eles. Salienta-se que esses fatores foram selecionados com base nos pressupostos enunciados por Berger e Luckmann (2003) sobre a formação do conhecimento do cotidiano, descritos no referencial teórico desta pesquisa. Como estratégia de análise dos dados coletados nesse bloco, foram utilizadas técnicas de estatística descritiva.

No terceiro bloco, as questões foram estruturadas buscando verificar o perfil dos respondentes, mais especificamente com relação ao gênero e à faixa de idade dos respondentes. Já no quarto bloco, foi solicitado aos respondentes, por meio de fotoquestionário desenvolvido por Azevedo (2010), também utilizado no estudo de Leal et al. (2014), que optassem pela imagem que melhor descrevesse suas percepções sobre o profissional contábil com relação aos seguintes temas: comunicação, criatividade, dedicação aos estudos, ética, liderança, propensão ao risco e trabalho em equipe. A Figura 1 exemplifica como as imagens foram apresentadas no instrumento de pesquisa.

As figuras, como o exemplo apresentado na Figura 1, buscam identificar se os respondentes possuem percepção negativa (A e D), neutra (B e E) ou positiva $(C$ e $F)$ do profissional contábil com relação às temáticas abordadas. Como é possível notar no excerto apresentado na Figura 1, as figuras também possibilitam verificar se existe um estereótipo relacionado ao gênero desse profissional. Em suma, o fotoquestionário permite obter informações sobre um fenômeno complexo de forma simplificada, proporcionando aproximação da realidade concreta da psicológica (AZEVEDO, 2010), método iconográfico considerado recomendado para o reconhecimento de uma representação social (RIBEIRO; ANTUNES-ROCHA, 2016). 
Figura 1 - Trecho do fotoquestionário para verificação da percepção dos respondentes a respeito da ética do profissional contábil
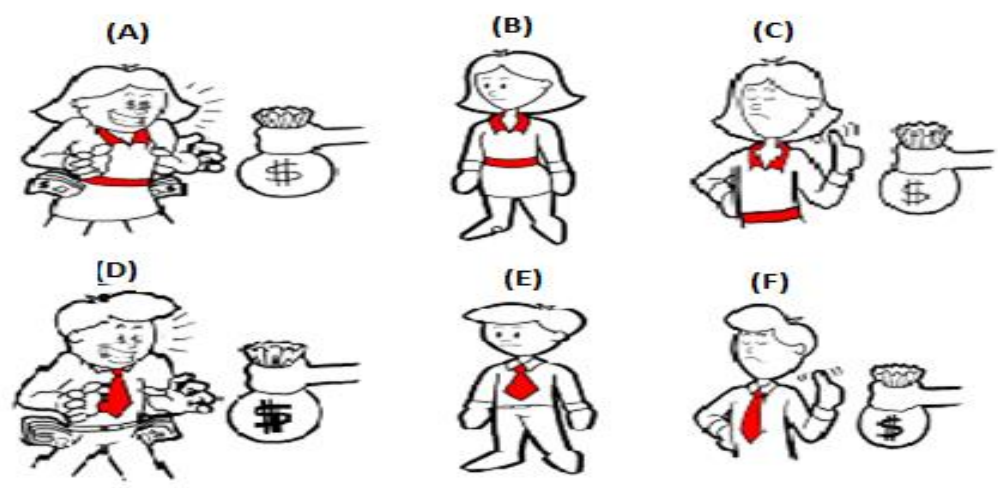

Fonte: Extraído de Azevedo (2010, p. 60).

Para análise desse bloco, assim como ocorreu no segundo bloco, foi lançado mão de técnicas de estatística descritiva. Vale ressaltar que a utilização do fotoquestionário foi precedida de autorização dada pelo autor responsável pela dissertação e que desenvolveu a ferramenta.

A coleta de dados ocorreu entre os meses de novembro e dezembro de 2012, cuja amostra não probabilística e intencional foi formada por 41 estudantes matriculados no último período de graduação em Ciências Econômicas de uma universidade pública sediada na região Sul do Brasil. A escolha por alunos pertencentes ao último ano de graduação em Ciências Econômicas se justifica pela maior proximidade e tempo de experiência no mercado de trabalho e em atividades acadêmicas interdisciplinares, o que presumivelmente possibilita maiores condições para que esses tenham formulado determinadas percepções sobre o profissional contábil, incluindo as percepções positivas e negativas obtidas durante o próprio curso de graduação.

\section{Análise de Dados}

Conforme elucidado na descrição dos procedimentos metodológicos adotados para a investigação, o primeiro bloco do questionário aplicado aos estudantes de Ciências Econômicas objetos do estudo teve por objetivo captar sua percepção a respeito do profissional de Contabilidade para que, na sequência, as respostas pudessem ser transcritas e analisadas à luz da técnica do discurso do sujeito coletivo. Seguindo os passos descritos anteriormente, inicialmente foram identificadas as expressões-chave dos discursos individuais.

Dessa forma, 130 expressões-chave foram identificadas e, na sequência, agrupadas de acordo com ideias centrais: (i) perfil do contador; (ii) função do contador; (iii) conhecimentos dominados; (iv) mercado de trabalho; e (v) formação da opinião do respondente. A distribuição das observações em cada categoria é apresentada na Figura 2.

Como é possível notar na Figura 2, os elementos relacionados ao perfil dos contabilistas foram os mais lembrados. Tais elementos envolveram aspectos morais, emocionais e de relacionamentos interpessoais. Nessa categoria, a expressão mais citada $(14,3 \%)$ foi "metódica", seguido por "gosta de estar isolado" $(7,1 \%)$ e "responsável" $(7,1 \%)$. 


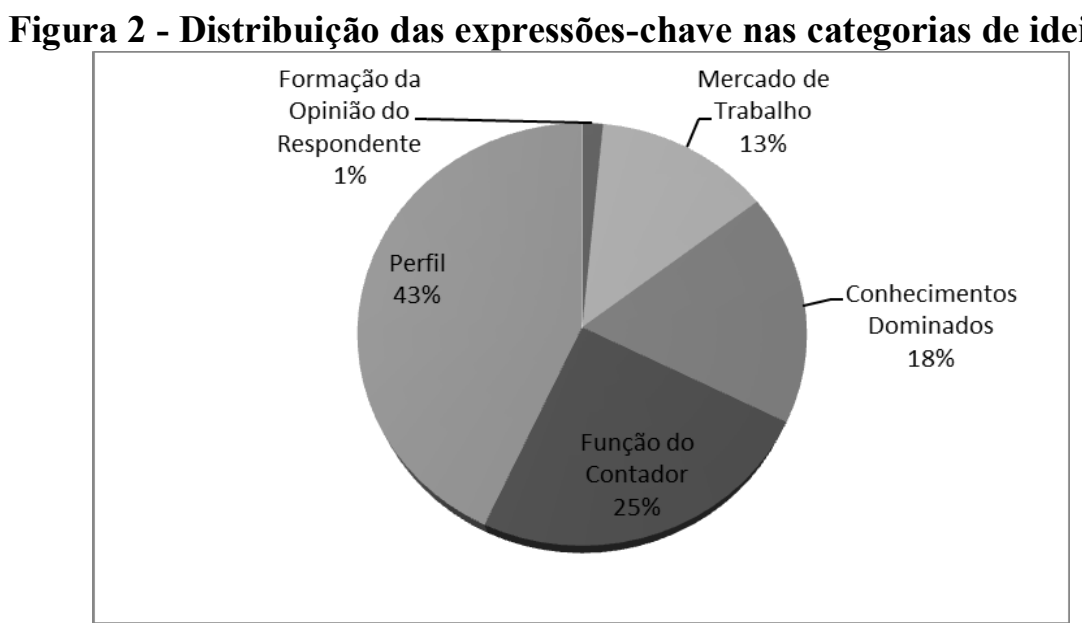

Fonte: Elaborada pelos autores (2015).

$\mathrm{Na}$ sequência, observa-se que foram apresentados elementos relativos à função do profissional contábil: $18,8 \%$ dos respondentes utilizaram expressões que convergiam para apontar o controle e a análise do fluxo de caixa da empresa como função desse profissional.

Com relação à categoria "mercado de trabalho", 23,5\% dos respondentes demonstraram acreditar que o profissional contábil deve atuar no setor financeiro das corporações, sendo indispensável nestas. Dentre as expressões que remetem ao conhecimento do profissional em questão, prevalece a visão de bons conhecimentos em matemática $(21,7 \%)$, legislação (17,4\%), finanças empresariais (13\%) e conhecimentos técnicos (13\%). Observouse que apenas $1 \%$ das expressões estava vinculada aos fatores que justificassem as opiniões expressas sobre os profissionais de Contabilidade, sendo descrita pelo mercado de trabalho, porém, esses fatores foram mapeados no segundo bloco do questionário, o que é detalhado nas análises subsequentes.

Como salientado na metodologia, todas as expressões compõem o discurso coletivo. A descrição acima apenas remete aos conceitos que foram lembrados com mais frequência pelos inquiridos. Desse modo, a imagem socialmente construída dos profissionais contábeis por estudantes de Ciências Econômicas pode ser expressa pelo discurso formado com base nas expressões-chave, conforme disposto a seguir:

Imagino uma pessoa careca, de meia-idade, acima do peso, usando óculos. Um profissional com muita ética, mas existem muitos que ainda agem desrespeitando as leis. Gosta de trabalhar isolado, porém é acessível e tem facilidade de trabalhar em grupo e organizar equipes. Utiliza linguagem técnica, termos e cálculos difíceis de entender. É normal, como qualquer pessoa da área de Ciências Sociais, com muito profissionalismo. Tem como características marcantes a responsabilidade, seriedade, objetividade e é um profissional confiável e centrado. Também é metódico, detalhista, rigoroso, paciente, ágil e atento. É um burocrata, corajoso, calculista de raciocínio não tão rápido. A criatividade não faz parte do seu dia a dia e por vezes pode não observar questões à sua volta, faltando visão holística. Pouco amante de risco, não possui aspecto empreendedor como o economista e o administrador e não se dedica com muito esforço às empresas (clientes).

Trabalha com muitos documentos, planilhas, fazendo muitos cálculos. Ele lida com assuntos ligados à administração pública, realiza os procedimentos de acordo com a legislação, é responsável por gerir dados fiscais da empresa, enfim, faz o que a Receita Federal manda. Esse profissional também é responsável pelo mapeamento e 
pela análise das relações de uma empresa com ela mesma e com as outras. Realiza os procedimentos de acordo com os interesses do cliente. Formula Balanços e DRE, controla e analisa o fluxo financeiro, administra toda a gestão de caixa e os dados gerenciais de uma empresa. É apto para dar valor a bens intangíveis e realizar o controle de ativos e passivos de uma empresa. Ele possui conhecimento técnico e prático agregado, tendo conhecimento afiado em legislação, tributos, finanças empresariais e também possui bom conhecimento em matemática, mas possui dificuldade de enxergar as finanças fora da "visão contábil".

O profissional contábil pode atuar em uma vasta gama de empresas, observando a relação quantitativa e monetária entre elas. Esse tem o seu escritório de Contabilidade e presta serviços às empresas. Possui um bom mercado de trabalho, bem definido, é útil ao ambiente corporativo e atua na área financeira sendo indispensável para empresas nessa área devido à exigência de profissionais com o CRC. O trabalho desse profissional é difícil, cansativo, nada interessante e nada inovador, uma vez que segue a legislação. Ressalta-se que, hoje em dia, com os softwares, pode ser substituído por profissionais de outras formações tendo, assim, um campo de trabalho mais restrito que outras áreas afins.

Tenho essa visão do profissional contábil devido a experiências profissionais.

No segundo bloco foram abordadas questões que possibilitassem mais compreensão sobre o processo de formação no discurso enunciado, sendo investigado o grau de conhecimento em Contabilidade na percepção dos respondentes, além do grau de contato com estudantes e profissionais de Contabilidade. Assim, foi observado que aproximadamente $60,9 \%$ dos estudantes consideram que possuem conhecimento razoável em Contabilidade, enquanto $21,9 \%$ consideram possuir um nível ruim de conhecimento e os demais $12,2 \%$ acreditam ter um bom nível de conhecimento em Contabilidade. Cerca de $63 \%$ dos respondentes afirmam ser o curso de graduação em Ciências Econômicas sua maior fonte de conhecimento na referida área, seguido pelo mercado de trabalho (19,5\%) e outras alternativas alcançaram menos de $5 \%$ de participação.

Todos os respondentes afirmam ter cursado disciplinas relacionadas à Contabilidade durante a graduação em Ciências Econômicas. Desses, 56,1\% mencionaram que tiveram, aproximadamente, entre 40 e 60 horas de disciplinas com o conteúdo citado, e 29,9\% acreditam ter cursado mais de 60 horas de disciplinas relacionadas à Contabilidade. Ressaltase, ainda, que $68,3 \%$ estudantes entrevistados afirmam ter cursado tais disciplinas tendo como professores docentes formados em Ciências Contábeis.

Com relação às atividades acadêmicas realizadas, a maioria dos respondentes $(75,6 \%)$ declarou não ter participado de projetos de iniciação científica. Ainda assim, 41,6\% dos estudantes afirmam ter tido contato com graduandos em Ciências Contábeis. Outro dado relevante refere-se ao fato de $90 \%$ dos respondentes terem, durante o curso de graduação em Ciências Econômicas, atuado no mercado de trabalho. Desses, aproximadamente 49\% atuaram na área de finanças; $18,9 \%$, em controladoria; 5,41\%, em ensino e pesquisa; e 27,3\%, em outras áreas. Destaca-se que $51,2 \%$ desses estudantes tiveram contato com contadores de maneira frequente, e 29,3\% afirmaram que esse contato era raro.

Com o objetivo de identificar como os estudantes de economia compreendem as Ciências Contábeis, solicitou-se que os respondentes indicassem seu grau de concordância, por meio de escala Likert, sobre algumas afirmações relacionadas à Contabilidade. Verificouse que $95 \%$ dos respondentes concordam (63\% totalmente e $32 \%$ parcialmente) que a Contabilidade é uma ferramenta destinada a mostrar as movimentações financeiras das empresas em um determinado momento do tempo. Também se observou que $66 \%$ concordam 
(15\% totalmente e $51 \%$ parcialmente) que a Contabilidade tem como principal propósito cumprir a legislação tributária. Aproximadamente $58 \%$ dos respondentes (24\% totalmente e $34 \%$ parcialmente) concordam que a Contabilidade está mais relacionada às Ciências Exatas, e $44 \%$ dos respondentes (10\% totalmente e $34 \%$ parcialmente) que a Contabilidade é uma ciência que se relaciona de forma interdisciplinar com a Sociologia, Psicologia, Linguística, Economia e Administração na busca de compreender o processo de tomada de decisão.

Com relação ao mapeamento do perfil dos respondentes, ao qual foi dedicado o terceiro bloco do questionário, essa seção buscou verificar a distribuição da amostra escolhida para a investigação com relação ao gênero e à faixa de idade dos respondentes. Notou-se, com base nos questionários respondidos, que a maioria dos respondentes pertence ao gênero masculino $(65,9 \%)$, enquanto $34,1 \%$ pertencem ao sexo feminino. Já em relação à idade, a ampla maioria dos respondentes estava, no momento da resposta aos questionários, na faixa de 20 a 25 anos $(80,4 \%)$, enquanto o restante dos respondentes estava distribuído nas faixas de 26 a 30 anos $(9,8 \%)$ e acima de 30 anos $(9,8 \%)$.

No quarto bloco, foi mapeada, por meio de fotoquestionário, a percepção dos respondentes com relação aos contabilistas quanto às categorias: comunicação, criatividade, dedicação aos estudos, ética, liderança, propensão ao risco e trabalho em equipe. A compilação dos resultados obtidos, com base no fotoquestionário, pode ser observada na Tabela 1.

Tabela 1 - Resultado de respostas ao fotoquestionário aplicado aos graduandos em Ciências Econômicas

\begin{tabular}{|c|c|c|c|c|}
\hline Categoria & Gênero & $\begin{array}{c}\text { Percepção } \\
\text { Negativa }\end{array}$ & Posição Neutra & $\begin{array}{c}\text { Percepção } \\
\text { Positiva }\end{array}$ \\
\hline \multirow{3}{*}{ Comunicação } & Feminino & $12,20 \%$ & & $2,44 \%$ \\
\hline & Masculino & $19,51 \%$ & & $4,88 \%$ \\
\hline & TOTAL & $31,71 \%$ & $60,98 \%$ & $7,32 \%$ \\
\hline \multirow{3}{*}{ Criatividade } & Feminino & $26,83 \%$ & & $7,32 \%$ \\
\hline & Masculino & $34,15 \%$ & & $2,44 \%$ \\
\hline & TOTAL & $60,98 \%$ & $29,27 \%$ & $9,76 \%$ \\
\hline \multirow{3}{*}{ Dedicação aos Estudos } & Feminino & $4,88 \%$ & & $39,02 \%$ \\
\hline & Masculino & $2,44 \%$ & & $17,07 \%$ \\
\hline & TOTAL & $7,32 \%$ & $36,59 \%$ & $56,10 \%$ \\
\hline \multirow{3}{*}{ Ética } & Feminino & $17,07 \%$ & & $17,07 \%$ \\
\hline & Masculino & $12,20 \%$ & & $9,76 \%$ \\
\hline & TOTAL & $29,27 \%$ & $43,90 \%$ & $26,83 \%$ \\
\hline \multirow{3}{*}{ Liderança } & Feminino & $12,20 \%$ & & $4,88 \%$ \\
\hline & Masculino & $9,76 \%$ & & $4,88 \%$ \\
\hline & TOTAL & $21,95 \%$ & $68,29 \%$ & $9,76 \%$ \\
\hline \multirow{3}{*}{ Propensão ao Risco } & Feminino & $31,71 \%$ & & $2,44 \%$ \\
\hline & Masculino & $17,07 \%$ & & $7,32 \%$ \\
\hline & TOTAL & $48,78 \%$ & $41,46 \%$ & $9,76 \%$ \\
\hline \multirow{3}{*}{ Trabalho em Equipe } & Feminino & $17,07 \%$ & & $17,07 \%$ \\
\hline & Masculino & $19,51 \%$ & & $17,07 \%$ \\
\hline & TOTAL & $36,59 \%$ & $29,27 \%$ & $34,15 \%$ \\
\hline
\end{tabular}

Fonte: Elaborada pelos autores (2015).

É possível observar, na Tabela 1, uma percepção negativa fortemente evidenciada com relação ao profissional contábil nos aspectos relacionados à criatividade e propensão ao risco, além de uma posição neutra - entretanto com maior tendência a uma percepção negativa -

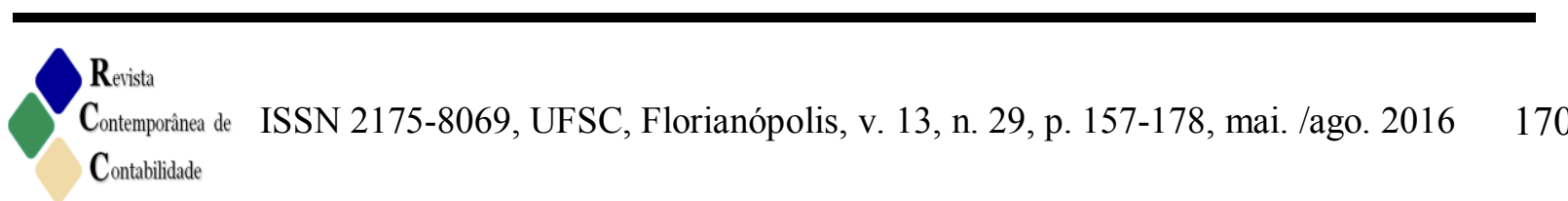


para os aspectos de comunicação e liderança, resultados estes que se diferenciam do observado por Azevedo (2010) e Leal et al. (2014), que não observaram percepções negativas para nenhuma das variáveis presentes no fotoquestionário Nos aspectos relacionados à ética $\mathrm{e}$ ao trabalho em equipe, nota-se que houve um padrão de respostas semelhantes, tanto para aspectos positivos quanto para aspectos negativos. Já para os fatores relacionados à dedicação aos estudos, a percepção dos estudantes de graduação em Ciências Econômicas é fortemente positiva. Como também é possível notar na Tabela 1, os padrões de respostas ao fotoquestionário não indicam a existências de estereótipos ligados a gênero, de acordo com a percepção dos estudantes entrevistados, diferentemente do observado em Leal et al. (2014), que identificaram estereótipos ligados ao gênero masculino na percepção pública.

\section{Conclusões}

A Teoria das Representações Sociais defende que o ser humano adquire conhecimento relativo ao cotidiano por meio de processos de interações sociais, formando assim percepções sobre o mundo que o cerca. De acordo com essa teoria, tal processo ocorre de forma recursiva, isto é, as interações afetam a forma de ver o mundo e essa percepção afeta as relações sociais. Tendo como base essa orientação teórica, a presente pesquisa buscou identificar qual a imagem do profissional contábil socialmente construída por estudantes de graduação em Ciências Econômicas. Para atingir o objetivo proposto, foi elaborado e aplicado um questionário composto por quatro blocos, buscando verificar a composição do discurso do sujeito coletivo da amostra e os possíveis determinantes dessa percepção de imagem do profissional contábil.

Por meio da análise do discurso do sujeito coletivo, foi possível identificar que o discurso dos futuros economistas se diferencia dos achados de Dias e Martins (2005), tendo em vista que o grupo inquirido acredita que os contabilistas possuem capacidade para valorar ativos e passivos, tangíveis e intangíveis. Porém, nos aspectos ligados à idoneidade e ética do profissional contábil, o discurso dos estudantes vai ao encontro com o indicado nas investigações de Dias e Martins (2005), Guerra et al. (2011) e Reis et al. (2015) a respeito da percepção favorável ao contabilista a respeito desses quesitos, mesmo tais pesquisas envolvendo públicos diferentes.

Com relação às pesquisas internacionais, o discurso aqui apresentado se aproxima dos resultados dos trabalhos de Robert (1957) e Stacey (1958), com menções relacionadas à habilidade para cálculos e o comportamento metódico dos contadores. No tocante aos aspectos emocionais, detectou-se substancial diferença entre os estudos que abordaram esses aspectos, pois o contabilista foi descrito como alguém que gosta de trabalhar sozinho, mas é acessível e capaz de trabalhar em grupo e organizar equipes, diferentemente das descrições de alguém sem habilidades sociais contidas nos trabalhos de Descoser e Rhode (1971) e Aranya et al. (1989). Já com relação aos aspectos físicos, a descrição dos estudantes é análoga às contidas nas pesquisas de Cory (1992), Beard (1994), Holt (1994) e de Smith e Briggs (1999), uma vez que, o contabilista foi descrito como "[...] uma pessoa careca, de meia-idade, acima do peso, usando óculos".

Ainda que os inquiridos entendam que a gestão financeira empresarial é responsabilidade dos contadores, observou-se que prevalece a vinculação da Contabilidade com questões tributárias e legais, como já observado no estudo de Splitter e Borba (2014) e 
Oliveira (2014), podendo ser esse um forte elemento que faz com que os estudantes de graduação em Ciências Econômicas vejam os profissionais em Contabilidade como não criativos e que realizam atividades difíceis, necessárias, mas não interessantes. A percepção do campo e atuação da Contabilidade também pode estar relacionada ao baixo conhecimento dessa ciência e do campo de atuação dos contabilistas, o que foi demonstrado pelos respondentes por meio do questionário aplicado. Ainda, a visão exposta pelos respondentes a respeito das atividades dos profissionais contábeis pode estar ligada à grande demanda de profissionais da área para o atendimento de questões fiscais e tributárias, o que faz com que uma grande quantidade de contabilistas se dedique a essa função (COELHO, 2001; PIRES; OTT; DAMACENA, 2009; SANTOS et al., 2015).

A análise realizada pela aplicação do fotoquestionário teve por objetivo descrever se a imagem do profissional contábil é positiva ou negativa, pelo qual se constatou a identificação de estereótipo positivo apenas para quantidade de horas de estudo. No entanto, deve-se considerar o elevado nível de respostas com posições neutras em praticamente todas as alternativas, sendo um indício de que, ao serem submetidos a classificações pré-organizadas, os respondentes demonstraram dúvidas, o que não ocorreu com as respostas à questão aberta. Todavia, destaca-se as tendências negativas apresentadas para os eixos de criatividade e propensão ao risco, o que não corrobora o observado em estudos semelhantes que aplicaram o fotoquestionário (AZEVEDO, 2010; LEAL et al., 2014).

De forma geral, verificou-se que os futuros economistas depositam confiança nos contabilistas, além de reconhecer a importância e complexidade do trabalho desses profissionais. No entanto, devido ao entendimento de que a Contabilidade está atrelada à legislação tributária, prevalece a noção de que os atuantes no campo contábil são desprovidos de criatividade e de visão holística. Por um lado, a imagem formada pelos estudantes de Ciências Contábeis favorece a confiabilidade dos futuros economistas nas informações contábeis. Por outro lado, os respondentes demonstram uma visão de que o campo de atuação profissional do contabilista, na área de negócios, pode ser dificultado, tendo como base a percepção sobre as atividades exercidas por esses profissionais.

Ressalta-se, assim, que é salutar que os profissionais em Contabilidade tenham conhecimento de como são vistos pelos futuros economistas, considerando o papel destes últimos no ambiente de atuação dos primeiros, e que seu trabalho, para ser adequadamente valorizado, precisa transmitir uma imagem positiva, o que implica ressaltar as percepções positivas e mitigar possíveis efeitos negativos de determinadas percepções que desvalorizem a atividade e os profissionais de Contabilidade.

Como apresentam Ribeiro e Antunes-Rocha (2016), o conhecimento da representação social formulada por determinado grupo é elemento que pode auxiliar na elaboração de estratégias de comunicação. Nesse sentido, espera-se que os resultados apresentados neste artigo, em conjunto com o observado em pesquisas correlatas, instiguem a atuação dos diversos órgãos representativos da classe contábil (como o Conselho Federal de Contabilidade e os Conselhos Regionais de Contabilidade, a Academia Brasileira de Ciências Contábeis, dentre outros) no sentido de realizar ações de melhoria da imagem do profissional contábil para a sociedade em geral e especialmente com profissionais diretamente interessados na atividade contábil dentro e fora das empresas, enfatizando o papel cada vez mais estratégico desse profissional nas entidades públicas e privadas, e cada vez menos restrito ao cumprimento da legislação tributária. Reforçam-se, dessa forma, as sugestões já realizadas por Splitter e Borba (2014) quanto ao importante papel dos profissionais contábeis e dos 
órgãos representativos para que seja possível a realização de mudanças nessa imagem socialmente construída, o que se acentua para a necessidade de ações com o grupo de profissionais e acadêmicos em Ciências Econômicas, haja vista a existência de percepções negativas que não foram observadas nos estudos de Azevedo (2010) e Leal et al. (2014).

Também é importante evocar o papel dos acadêmicos na área das Ciências Contábeis ao terem condições de dirimir tal vinculação desfavorável com os estudantes de graduação de outras áreas de atuação, demonstrando, ao longo das disciplinas ministradas, o papel cada vez mais estratégico dos contabilistas nas organizações, para que assim eles possam levar das salas de aula uma imagem diferenciada para o mercado de trabalho, tendo em vista o aprimoramento das relações profissionais entre os profissionais das distintas áreas do conhecimento.

A importância da realização dessas iniciativas leva em consideração o exposto por Jovchelovicht (2000) a respeito das representações sociais, já que a ideia ou interpretação socialmente construída por um grupo sobre determinados indivíduos é capaz de influenciar a forma com que o grupo se relacionará com tais sujeitos, constituindo um processo de influência simultânea entre estes, o que é especialmente relevante ao considerar a importância dos economistas nas atividades dos contabilistas, como no tratamento do custo de capital para avaliações e projeções, e a importância do contabilista para a atividade do economista, como nas atividades relacionadas a finanças e mercado de capitais.

Quanto às possibilidades acadêmicas, os achados da presente pesquisa sugerem a necessidade de se realizarem novos estudos que abordem a postura dos profissionais contábeis nas empresas e nas instituições de ensino superior, uma vez que a maioria dos respondentes afirma ter tido contato frequente com contadores, especialmente no mercado profissional. Torna-se igualmente importante investigar a qualidade e conteúdo das disciplinas de Ciências Contábeis ministradas ao curso de Ciências Econômicas, tendo em vista os indícios de máformação na área, apresentados nos resultados desta pesquisa, bem como para o esclarecimento dos motivos que levam esse grupo de profissionais possuir tal percepção a respeito do profissional contábil.

Uma possível limitação dos resultados apresentados neste artigo está relacionada ao período no qual a coleta de dados foi realizada, o que ocorreu entre novembro e dezembro de 2012. Todavia, acredita-se que os achados possam ainda ser considerados relevantes e contemporâneos acerca do relacionamento e da representação social formulada por graduandos e graduados em Ciências Econômicas, visto que mudanças, relevantes no processo formativo em ambos os cursos, não podem ser apontadas desde o período da realização das atividades de campo até a publicação do artigo, bem como ao observar que estudos recentes realizados com grupos externos à profissão ainda tendem a vincular a imagem do contador ao "guarda-livros" (OLIVEIRA, 2014; SPLITTER; BORBA, 2014).

Quanto ao processo de convergência dos padrões brasileiros de contabilidade aos padrões internacionais de contabilidade, o que suscitou uma mudança de paradigmas na profissão contábil a partir de 2008 e nos currículos acadêmicos desde então, e que é capaz de motivar uma visão diferente da profissão contábil pelos seus stakeholders, não pode ser considerada plenamente institucionalizada à época da realização da coleta de dados, com reflexos plenos em âmbito acadêmico e profissional, haja vista a existência de inibidores à convergência aos padrões internacionais com relação à conduta do profissional brasileiro (ESPEJO et al., 2010). 
Dessa forma, sugere-se a realização de um novo estudo, baseado na Teoria das Representações Sociais, após a efetiva institucionalização do processo de convergência dos padrões locais aos padrões internacionais de contabilidade, buscando verificar se tal processo suscitou mudanças na imagem do profissional contábil com os graduandos de Ciências Econômicas, lembrando que, conforme citam Ribeiro e Antunes-Rocha (2016), a aplicação da teoria das representações sociais auxilia no entendimento das mudanças de comportamento entre os grupos sociais.

\section{Agradecimento}

Os autores agradecem à Prof $\mathrm{f}^{\mathrm{a}}$. Silvia Pereira de Castro Casa Nova (Universidade de São Paulo) pelas sugestões dadas para o aprimoramento deste artigo.

\section{Referências}

ALLEN, Cheryl L. Business students' perception of the image of accounting. Managerial Auditing Journal, v. 19, n. 2, p. 235-258, 2004.

ALBRACHT, W. Steve; SACK, Robert J. Accounting education: charting the course through a perilous future. Sarasota: American Accounting Association, 2000.

ARANYA, Nissim; MEIR, Elchanan I.; BAR-ILAN, Avraham. An empirical examination of the stereotype accountant based on Holland's theory. Journal of Occupational Psychology, v. 51, n. 2, p. 139-145, 1989.

AZEVEDO, Renato Ferreira Leitão. A percepção pública sobre os contadores: bem ou mal na foto? 2010. Dissertação (Mestrado em Controladoria e Contabilidade: Contabilidade) Faculdade de Economia, Administração e Contabilidade, Universidade de São Paulo, São Paulo, 2010. Disponível em: <http://www.teses.usp.br/teses/disponiveis/12/12136/tde28102010-165136/>. Acesso em: 7 jul. 2015.

AZEVEDO, Renato Ferreira Leitão; CORNACCHIONE, Edgard Bruno, Jr; CASA NOVA, Silvia Pereira de Castro. A percepção dos estudantes sobre o curso e o perfil de dos estudantes de contabilidade: uma análise comparativa das percepções e estereotipagem. In:

CONGRESSO USP DE CONTROLADORIA E CONTABILIDADE, 8., 2008, São Paulo, Anais... USP, 2008.

BALDVINSDOTTIR, Gudrun et al. The image of accountants: from bean counters to extreme accountants. Accounting, Auditing \& Accountability Journal, v. 22, n. 6, p. 858-882, 2009.

BEARD, Victoria. Popular culture and professional identity: accountants in the movies. Accounting, Organizations and Society, v. 19, n. 3, p. 303-318, 1994. 
BERGER, Peter L.; LUCKMANN, Thomas. A construção social da realidade. 29. ed. Petrópolis: Vozes, 2003.

CARNEGIE, Garry D.; NAPIER, Christopher J. Traditional accountants and business professional: portraying the accounting profession after Enron. Accounting, Organizations and Society, v. 35, n. 3, p. 360-376, 2010.

CHANG, Emily Chen. Business income in accounting and economics. The Accounting Review, v. 37, n. 4, p. 636-644, 1962.

COELHO, Cláudio Ulysses Ferreira. Uma Análise do ensino superior de contabilidade e do mercado de trabalho no município do Rio de Janeiro. Pensar Contábil, v. 4, n. 11, 2001. (Não paginado.)

CORY, Suzanne N. Quality and quantity of accounting students and the stereotypical accountant: is there a relationship? Journal of Accounting Education, v. 10, n. 1, p. 1-24, 1992.

DECOSTER, Don T.; RHODE, John G. The accountants stereotype: real or imagined, deserver or unwarranted. The Accounting Review, v. 16, n. 4, p. 651-664, 1971.

DIAS, Guadalupe Machado; MARTINS, Gilberto de Andrade. Representações sociais e imaginário coletivo na contabilidade. Revista Contemporânea de Contabilidade, v. 2, n. 4, p. 9-31, 2005.

DIMKIT, Tony; FELTON, Sandra. Accounting stereotypes in movies distributed in North America in the twentieth century. Accounting, Organizations and Society, v. 31, n. 2, p. 129-155, 2006.

DIPTYANA, Pepie; DJUWARI, A. Students perception toward accountant personality in accounting department and management department: a case study at STIE Perbanas Surabaya. In: ANNUAL SEAAIR CONFERENCE, 7., 2007, Bangkok, Anais... SEAAIR, 2007.

ESPEJO, Márcia Maria dos Santos Bortolocci et al. Uma abordagem institucional do subjetivismo responsável na adoção das normas internacionais de contabilidade: uma análise crítico-reflexiva sobre os inibidores à convergência no Brasil. Estudos do ISCA, n. 2, p. 123, 2010.

EVANS, Lisa; FRASER, Ian. The accountant's social background and stereotype in popular culture: the novels of Alexander Clark Smith. Accounting, Auditing \& Accountability Journal, v. 25, n. 6, p. 964-1000, 2012.

FERREIRA, Aurelio Buarque de Holanda. Novo dicionário Aurélio da língua portuguesa. 5. ed. Curitiba: Positivo, 2010. 
FERREIRA, Maria Cristina. A psicologia social contemporânea: principais tendências e perspectivas nacionais e internacionais. Psicologia: Teoria e Pesquisa, v. 26, p. 51-64, 2010.

FRANCISCO, William H.; NOLAND, Thomas G.; KELLY, J. Ann. Why don't students major in accounting? Southern Business Review, v. 29, n. 1, p. 37-40, 2003.

FRIEDMAN, Andrew L.; LYNE, Stephen R. The bean counter stereotype: towards a general model of stereotype generation. Critical Perspectives on Accounting, v. 12, n. 4, p. 423-451, 2001.

GAMA, Adriana Ferreira; SANTOS, Aline Renée Benigno dos; FOFONCA, Eduardo. Teoria das representações sociais: uma análise crítica da comunicação de massa e da mídia. Revista Eletrônica Temática, v. 6, n. 10, 2010.

GONDIM, Sonia Maria Guedes; FISCHER, Tania. O discurso, a análise de discurso e a metodologia do discurso do sujeito coletivo na gestão intercultural. Cadernos Gestão Social, v. 2, n. 1, p. 9-26, 2009.

GUERRA, Gilberto Clarício Martinez et al. A representação social da profissão de contador na perspectiva dos profissionais da contabilidade. Revista de Contabilidade e Organizações, v. 5, n. 12, p. 157-171, 2011.

GUERREIRO, Reinaldo. Mensuração do resultado econômico. Caderno de Estudos FIPECAFI, n. 3, p. 1-11, 1991.

HENDRIKSEN, Eldon S.; VAN BREDA, Michael F. Teoria da Contabilidade. São Paulo: Atlas, 1999.

HOLT, P. E. Stereotypes of the accounting professional as reflected in popular movies, accounting students and society. New Accountant, v. 9, n. 7, p. 24-25, 1994.

HOOPER, K.; KEARINS, K.; WELLS, P. Tax agent, bean counter or cost controller: what do clients think of accountants? In: AFAANZ Conference, 2009. Adelaide. Anais... AFAANZ, 2009.

HUNT, Steven C.; FALGIANI, Anthony A.; INTRIERI, Robert C. The nature and origins of students' perceptions of accountants. Journal of Education for Business, v. 79, n. 3, p. 142148, 2004.

JEACLE, Ingrid. Beyond the boring grey: the construction of the colorful accountant. Critical Perspectives on Accounting, v. 19, n. 8, p. 1296-1320, 2008.

JODELET, Denise. Representações sociais: um domínio em expansão. In: JODELET, Denise. (Org.), As Representações Sociais. Rio de Janeiro: UERJ, 2001. 
JOVCHELOVITCH, Sandra. Representações sociais e esfera pública: a construção simbólica dos espaços públicos no Brasil. Petrópolis: Vozes, 2000.

LEAL, Edvalda Araujo et al. Estereótipos na profissão contábil: a opinião de estudantes e do público externo no Triângulo Mineiro. Contabilidade, Gestão e Governança, v. 17, n. 1, p. 134-153, 2014.

LEFEVRE, Fernanda; LEFEVRE, Ana Maria Cavalcanti. Depoimentos e discursos: uma proposta de análise em pesquisa social. Brasília: Liber, 2005.

MARTINS, Gilberto de Andrade; THEÓPHILO, Carlos Renato. Metodologia da investigação científica para ciências sociais aplicadas. São Paulo: Atlas, 2007.

MOLINER, Pascal; GUIMELLI, Christian. Les représentations sociales: fondements historiques et développements récents. Grenoble: Presses universitaires de Grenoble, 2015.

MOSCOVICI, Serge. A representação social da psicanálise. Rio de Janeiro: Zahar, 1978.

MOSCOVICI, Serge. Representações sociais: investigações em psicologia social. 5. ed. Petrópolis: Vozes, 2007.

NOEL, Noel Mark; MICHAELS, Chad; LEVAS, Michael G. The relationship of personality traits and self-monitoring behavior to choice of business major. Journal of Education for Business, v. 78, n. 3, p. 153-157, 2003.

OLIVEIRA, Márcia Regina de. O status social do contador no Brasil. 2015. Dissertação (Mestrado em Ciências Contábeis) - Universidade Presbiteriana Mackenzie, São Paulo, 2015.

PARKER, Lee David. Goodbye number cruncher! Australian CPA, v. 70, n. 2, p. 50-52, 2000.

PEPITONE, Albert. Lessons from the history of social psychology. American Psychologist, v. 36, n. 9, p. 972-985, 1981.

PIRES, Charline Barbosa; OTT, Ernani; DAMACENA, Claudio. "Guarda-livros" ou "parceiros de negócios"? Uma análise do perfil profissional requerido pelo mercado de trabalho para contadores na Região Metropolitana de Porto Alegre (RMPA). Contabilidade Vista \& Revista, v. 20, n. 3, p. 157-187, 2009.

REIS, Anderson de Oliveira et al. Perfil do profissional contábil: habilidades, competências e imagem simbólica. Revista Contemporânea de Contabilidade, v. 12, n. 25, p. 95-116, 2015.

REIS, Sebastiana Lindaura de Arruda; BELLINI, Marta. Representações sociais: teoria, procedimentos metodológicos e educação ambiental. Acta Scientiarum. Human and Social Sciences, v. 33, n. 2, p. 149-159, 2011. 
RIBEIRO, Luiz Paulo; ANTUNES-ROCHA, Maria Isabel. História, Abordagens, Métodos e Perspectivas da Teoria das Representações Sociais. Psicologia \& Sociedade, v. 28, n. 2 , 2016.

ROBERT, R. The accountant in literature. Journal of Accountancy, v. 103, p. 64-66, 1957.

ROGERS, Rodney K.; DILLARD, Jesse; YUTHAS, Kristi. The accounting profession: substantive change and/or image management. Journal of Business Ethics, v. 58, n. 1-3, p. 159-176, 2005.

SANTOS, Antonio dos et al. Mercado de trabalho para o profissional de contabilidade: perfil e oferta de vagas na região nordeste do Brasil. Revista Mineira de Contabilidade, v. 16, n. 2, p. 51-61, 2015.

SCHLEE, Regina Pefanis. et al. Perception bias among undergraduate business students by major. Journal of Education for Business, v. 82, n. 3, p. 169-177, 2007.

SPLITTER, Karla; BORBA, José Alonso. Percepção de estudantes e professores universitários sobre a profissão do contador: um estudo baseado na teoria dos Estereótipos.

Revista de Educação e Pesquisa em Contabilidade, v. 8, n. 2, p. 126-141, 2014.

SMITH, Malcolm; BRIGGS, Susan P. From bean-counter to action hero: changing the image of the accountant. Management Accounting, v. 77, n. 1, p. 28-30, 1999.

STACEY, Nicholas A. H. The accountant in literature. The Accounting Review, v. 33, n. 1, p. 102-105, 1958.

SUGAHARA, Satoshi; KURIHARA, Osamu; BOLAND, Gregory. Japanese secondary school teachers' perceptions of the accounting profession. Accounting Education: an International Journal, v. 15, n. 4, p. 405-418, 2006.

TEVES, Nilda; RANGEL, Mary. Representação social e educação: temas e enfoques contemporâneos de pesquisa. Campinas: Papirus, 1999.

VAIVIO, Juhani; KOKKO, Terhi. Counting big: re-examining the concept of the bean counter controller. The Finnish Journal of Business Economics, v. 6, n. 3, p. 49-74, 2006.

WATTS, Ross L.; ZIMMERMAN, Jerold L. Positive accounting theory. Englewood Cliffs: Prentice Hall, 1986. 